\title{
DA ROÇA PARA A ESCOLA: INSTITUCIONALIZAÇÃO E EXPANSÃO DAS ESCOLAS PRIMÁRIAS RURAIS NO PARANÁ $(1930-1960)$
}

\author{
Analete Regina Schelbauer \\ Universidade Estadual de Maringá, Brasil.
}

$\cos 80$

\begin{abstract}
Resumo
No âmbito do presente artigo propõe-se a compreender o processo de institucionalização e expansão das escolas primárias rurais no Estado do Paraná, Brasil, por meio das iniciativas empreendidas pelo governo estadual, suas relações com as diretrizes federais e as tematizações relacionadas à educação rural, entre as décadas de 30 a 60 do século 20 . Os documentos que deram suporte à investigação constituem-se das mensagens e relatórios de governadores estaduais e interventores federais, analisadas a partir da produção historiográfica sobre o tema. Tais documentos possibilitaram construir um quadro das ações governamentais acerca da educação rural, identificar o tratamento dado à temática da escola do meio rural, verificar os modelos de escolas criadas e analisar as particularidades que marcaram o ensino primário rural no Estado.

Palavras-chave: escola primária rural, educação rural, institucionalização e expansão do ensino rural, Estado do Paraná.

\section{FROM THE COUNTRYSIDE TO THE SCHOOL: INSTITUTIONALIZATION AND EXPANSION OF RURAL PRIMARY SCHOOLS IN PARANÁ (1930-1960)}

\section{Abstract}

This article proposes to understand the process of institutionalization and expansion of rural primary schools in Paraná, through the initiatives undertaken by the State government and its relationship with the federal dictates and themes related to rural education, between the $30^{\text {th }}$ and $60^{\text {th }}$ decades of $20^{\text {th }}$ century. The documentary sources that supported the research constitute the messages and reports of State governors and federal stakeholders of the State approached, examined from historical production on the subject. Such documents allowed to build a framework of government actions on rural education, identify the treatment given to the issue of rural school, check the arrangements for schools created and analyze the peculiarities that marked rural primary education in the State.

Key-words: rural primary school, rural education, institutionalization and expansion of rural education, Sate of Paraná. 


\title{
DEL CAMPO PARA LA ESCUELA: INSTITUCIONALIZACIÓN Y EXPANSIÓN DE LAS ESCUELAS PRIMARIAS RURALES EN EL PARANÁ
}

\begin{abstract}
Resumen
En este artículo se examina el proceso de institucionalización y expansión de las escuelas primarias rurales de Paraná, por intermedio de iniciativas emprendidas por el gobierno estatal comparado a los preceptos federales y las temáticas relacionadas a la educación rural entre los años 30 hasta 60 del siglo 20. Las fuentes documentales utilizadas en la investigación constituyen de los mensajes e informes de los gobernadores de los estados e interventores federales de este estado, analizados desde la producción historiografía sobre el tema. Tales documentos permiten construir un marco de acciones gubernamentales acerca de la enseñanza rural, identificar el tratamiento dado a este objeto, averiguar las peculiaridades de escuelas creadas y analizar las particularidades de que caracterizaron la enseñanza rural primaria en el Estado.

Palabras-clave: escuela primaria rural, educación rural, institucionalización y expansión de la enseñanza rural, Estado del Paraná.

\section{DE LA CAMPAGNE VERS L'ÉCOLE: INSTITUTIONNALISATION ET EXPANSION DES ÉCOLES PRIMAIRES RURALES DANS L'ÉTAT DE PARANA (1930-1960)}

\section{Résumé}

Cet article cherche à comprendre le processus d'institutionnalisation et l'expansion des écoles primaires rurales au État de Paraná, à travers les initiatives prises par le gouvernement de l'État et de ses relations avec les impératifs fédéraux et thématisations liés à l'éducation en milieu rural, les décennies entre les années 30 et 60 du siècle 20. Les sources documentaires qui ont soutenu la recherche constituent des messages et les rapports des gouverneurs des États et des intervenants fédéraux dans l'Etat en question, analysés à partir de la production historiographie sur le sujet. Ces documents ont permis de construire un cadre de l'action gouvernementale en matière d'éducation en milieu rural, d'identifier le traitement du thème de l'école rurale, vérifier les modèles d'écoles créés et d'analyser les particularités qui ont marqué l'enseignement primaire en milieu rural dans l'État.

Mots-clé: l'école primaire en milieu rural, l'éducation rurale, l'institutionnalisation et l'expansion de l'éducation rurale, l'État de Paraná. 
Nesta escola modesta da roça, rodeada de pés de café, o Brasil se levanta e recomeça numa nova alvorada de fé. Batida de sol ardente, quero saber o farol que nos guia para frente nesta bendita Escola Rural. ${ }^{1}$

epígrafe, com a letra de uma música cantada pelos alunos das escolas rurais
do Norte do Paraná em meados do século passado, faz parte das
reminiscências de uma população que foi escolarizada em um Estado predominantemente rural até os anos setenta do século 20 . Em pouco mais de quatro décadas esse modelo de escola primária tornou-se praticamente desconhecido entre as novas gerações, tanto em sua dimensão histórica, quanto em sua realidade atual.

Apesar de pouco conhecida, a escola de ensino fundamental, situada nas áreas rurais, continua a ser uma realidade na vida de milhares de crianças não só no Paraná2, como no Brasil e no contexto mundial da globalização. No recente dossiê publicado sobre Education e ruralités, os dados apresentados Gauthier e Luginbühl (2012) atestam para o fato de que quase metade da população mundial ainda vive em áreas rurais, bem como indicam a necessidade de uma reflexão sobre a educação que é ofertada e uma análise mais aprofundada das ruralidades que afetam o funcionamento das escolas rurais.

No Brasil, a pesquisa recente realizada pelo lbope e pelo Instituto Paulo Montenegro ${ }^{3}$ em dez Estados brasileiros, representantes das cinco regiões do país com o melhor e o pior resultado no Ideb, levantou informações sobre a estrutura e o funcionamento das escolas da zona rural, o cotidiano das famílias e as principais dificuldades enfrentadas por elas para manter as crianças na escola. Resultados indicam que a escola no meio rural é uma realidade em um país que possui $15,6 \%$ da população residente nas áreas rurais ${ }^{4}$, cuja maior concentração está situada nas regiões Norte e Nordeste, com $26,5 \%$ e $26,9 \%$ respectivamente, e sugerem a necessidade de análise sobre este modelo de escola.

Pautada nestas considerações iniciais, impõe-se uma questão: se a escola no meio rural ainda é uma realidade, tanto em âmbito internacional, quanto nacional, por que a história desta modalidade de ensino ainda é tão lacunar entre nós?

Damasceno e Beserra (2004), ao escreverem sobre as perspectivas e o estado da arte da educação rural no Brasil apontam, não só para a escassez de estudos sobre o tema, como para a necessidade da produção de estudos sobre a história da educação rural nas diversas regiões brasileiras. Em trabalho recente, Ávila (2013) apresenta o levantamento da produção acadêmica sobre a abordagem histórica da educação rural no

\footnotetext{
${ }^{1}$ A música faz parte das reminiscências de alunas e alunos do Curso Histórias de Vida, que ministrei na Universidade Aberta à Terceira Idade - Unati - da Universidade Estadual de Maringá no ano de 2010.

2 No Estado do Paraná, a escola do campo ficou definida como "aquela que se localiza nos perímetros rural e nos distritos dos municípios e recebem sujeitos oriundos do campo, tais como: pequenos agricultores, assentados, acampados, meeiros, posseiros, arrendatários, quilombolas, faxinalenses, bóias-frias, entre outros. Tais escolas foram normalizadas pelo parecer CEE/CEB n. 1.011/10, aprovado em 6 de outubro de 2010, pela Câmara de Educação Básica, que estabelece as normas e princípios para a implamtação da educação básica do campo no sistema estadual do ensino do Paraná, bem como o processo de definição da identidade das escolas do campo" (Paraná, 2010).

3 Ver Projeto Escolas Rurais, pesquisa realizada pelo Ibope Inteligência e Instituto Paulo Montenegro (2010), com exclusividade para o Serviço Nacional de Aprendizagem Rural, envolvendo os Estados da Bahia, Minas Gerais, Mato Grosso, Pará, Pernambuco, Paraná, Rio de Janeiro, Rio Grande do Sul, Tocantins e Distrito Federal.

${ }^{4}$ Ver sinopse do censo demográfico do IBGE (2010). Hist. Educ. [Online] $\quad$ Porto Alegre v. 18 n. 43 Maio/ago. 2014 p. $71-91$
} 
Brasil e constata dados inquietantes ao afirmar que, embora tenha encontrado estudos específicos que têm a educação rural como tema, permanece "a lacuna de estudos historiográficos relativos ao contexto em que se desenvolveram as políticas educacionais e a introdução de modelos educativos para o ensino primário rural no transcorrer do século 20 no Brasil" (p. 22).

No caso do Paraná as produções estão circunscritas a abordagens mais recentes sobre as escolas do campo e as escolas uni-docentes para a zona rural. Os estudos de caráter histórico estão focalizados nas políticas educacionais para tais escolas, na formação de professores para o meio rural, escolas de trabalhadores rurais, dentre outros temas mais específicos. No entanto, a leitura destas produções ${ }^{5}$ permite identificar nuances da temática em meio ao contexto paranaense das décadas de 1930 a 1960 , assim como evidenciam a necessidade de aprofundar a pesquisa sobre o processo de institucionalização e de expansão da escola primária no meio rural, o qual está inscrito de forma lacunar no âmbito da historiografia da educação paranaense.

Dada à relevância do tema e à produção lacunar acerca da escola primária rural no Estado, o presente artigo, que se insere no campo dos debates sobre a História e a historiografia da escola primária no Brasil, propõe compreender o processo de institucionalização e expansão das escolas primárias rurais no Paraná, em meio às tematizações relacionadas à educação rural entre as décadas de 30 a 60 do século 20 .

Ao dar primazia ao estudo do espaço rural, consideramos importante fazê-lo mediante as devidas correlações com o urbano, em suas contraposições, justaposições e interdependências. Como advertiu Graça Filho (2009), o próprio desenvolvimento do urbano depende da produção agrícola e de seu transporte, é o excedente agrícola que possibilita o nascimento do urbano. No caso específico do Paraná, isso pode ser observado ao longo do período estudado com os movimentos das migrações internas, sobretudo para a região Norte do Estado, vinculada ao plantio do café, o que estabeleceu uma forte correlação entre o mundo rural e o urbano.

Sob esta perspectiva de análise, realizamos a investigação com base na documentação encontrada nos arquivos e centros de documentação da capital do Estado, assim como na bibliografia relativa à história do Paraná, à história e historiografia da educação e sobre a temática específica do ensino rural. Definimos por trabalhar com os relatórios e as mensagens dos presidentes, interventores e governadores do Paraná, com o intuito de apreender as ações do governo quanto à institucionalização e expansão das escolas primárias rurais no período de 1930 a 1960, analisar o tratamento dado à temática da escola do meio rural, verificar os modelos de escolas criados, as iniciativas e particularidades que marcaram o ensino primário rural no Estado.

Por que os relatórios e mensagens de governo como documentos? Para responder esta questão reportamo-nos à argumentação contida no documento $O$ Paraná

\footnotetext{
${ }^{5}$ Ver Cainelli (1994), Capelo (2000, 2008), Pereira (2002), Passador (2006), Bareiro (2007), Miguel (2007, 2010, 2011), Marques e Farias (2010), Martiniak (2011), Tubucheski (2011), Pryjma (1999), dentre outros. 
reinventado: política e governo ${ }^{6}$, de que o caráter de determinados documentos produzidos pelo processo administrativo são mais instituintes do que instituídos:

A realidade é, assim, produzida pelo documento. Logo, é na construção discursiva do campo político que encontramos o sentido atribuído no gerenciamento da população. Os "projetos" políticos não se antecipam às práticas administrativas; pelo contrário, o discurso político busca imprimir uma lógica àquelas práticas, sem, contudo, esgotar seu próprio campo discursivo. (Ipardes, 1989, p. 1)

A análise de tais documentos, como adverte Le Goff (2012, p. 521), por representarem "uma montagem, consciente ou inconsciente, da história, da época, da sociedade que o produziram, mas também das épocas sucessivas durante as quais continuou a viver, talvez esquecido, durante as quais continuou a ser manipulado, ainda que pelo silêncio", exige uma postura que leve em consideração às condições concretas de produção destas fontes documentais, as quais abrangem questões econômicas, geográficas, sociais e políticas muito distintas.

As mensagens e os relatórios, por terem sua origem em um ato legal, configuram-se como documentos oficiais e, no caso do Paraná, fazem parte do acervo do Arquivo Público do Estado. Dentre a documentação analisada, foram identificados cinco relatórios e onze mensagens, identificadas no quadro que segue.

\section{Quadro 1}

Quadro resumido das mensagens e relatórios dos presidentes, governadores e interventores federais no Estado do Paraná (1930-1960).

\begin{tabular}{|l|c|c|c|}
\hline Documento & $\begin{array}{c}\text { Período de exercício ou } \\
\text { data de apresentação }\end{array}$ & $\begin{array}{c}\text { Presidente de Estado, governador, } \\
\text { interventor Federal em exercício no } \\
\text { Estado }\end{array}$ & $\begin{array}{c}\text { N. de } \\
\text { Páginas }\end{array}$ \\
\hline Relatório & $1924-1928$ & Presidente Caetano Munhoz da Rocha & 39 \\
\hline Relatório & 1932 a 1939 & Interventor federal Manoel Ribas & 186 \\
\hline Relatório & 1937 a 1942 & Interventor federal Manoel Ribas & 51 \\
\hline Relatório & 1940 a 1941 & Interventor federal Manoel Ribas & 162 \\
\hline Relatório & 1947 a 1950 & Governador Moysés Lupion & 400 \\
\hline Mensagem & $1 \% / 2 / 1930$ & Presidente de Estado Affonso Alves & 111 \\
\hline Mensagem & 1930 a 1931 & Camargo & 86 \\
\hline Mensagem & $18 / 5 / 1935$ & Interventor Mario Tourinho & 72 \\
\hline Mensagem & $1 \% / 9 / 1936$ & Governador Manoel Ribas & 117 \\
\hline Mensagem & $1 \% / 9 / 1937$ & Governador Manoel Ribas & 93 \\
\hline Mensagem & $1 \% / 5 / 1948$ & Governador Moysés Lupion & 145 \\
\hline Mensagem & $1 \% / 5 / 1950$ & Governador Moysés Lupion & 271 \\
\hline
\end{tabular}

${ }^{6}$ Documento elaborado a partir do Projeto história política do Paraná, desenvolvido por intermédio do convênio com Instituto Paranaense de Desenvolvimento Econômico e Social, Secretaria do Estado de Planejamento e Coordenação Geral, Fundação Universidade Estadual de Maringá. Equipe: coordenadora: Marionilde Dias Brephol de Magalhães, coordenador adjunto: Francisco Moraes Paes. Integrantes: Nelson Ari Cardoso, Wânia Savazzi Rizzi, Alfeo Luiz Capelarri, Marcos Antonio Cordiolli, Maria Lucia Cidade. Colaboradores: Ana Maria de Oliveira Burmester, Viviane Ribeiro. Consultor: Edgar Salvadori de Decca. 


\begin{tabular}{|l|c|c|c|}
\hline Mensagem & $1 \% / 5 / 1951$ & Governador Bento Munhoz da & 155 \\
\hline Mensagem & $1 \% / 5 / 1956$ & Rocha Neto & 230 \\
\hline Mensagem & $1 \% / 5 / 1957$ & Governador Moysés Lupion & 251 \\
\hline Mensagem & $1 \% / 5 / 1958$ & Governador Moysés Lupion & 265 \\
\hline
\end{tabular}

Fonte: Quadro elaborado com base nas informações contidas nas mensagens e relatórios pesquisados e citados na documentação.

Os relatórios dos interventores federais eram dirigidos ao presidente da República, em cumprimento a uma determinação federal, e os relatórios dos governadores, apresentados à Assembleia Legislativa do Estado ${ }^{7}$. Ambos contemplam uma descrição detalhada da administração pública referente ao exercício correspondente, apresentam um quadro das realizações, colocam em destaque as planificações e apontam os problemas pertinentes a cada um dos seguintes itens: finanças e economia, saúde pública, educação pública, justiça e segurança pública, edificação e obras públicas, saneamento, transportes, terras e colonização, produção e serviços científicos, com ênfase para produção agrícola e pecuária e destaque para o ensino agrícola, além de salientar os trabalhos desenvolvidos pelas secretarias estaduais.

As mensagens dos presidentes de Estado, dos interventores e dos governadores constituem-se em documentos enviados ao Congresso Legislativo e à Assembleia Legislativa por ocasião da abertura do ano legislativo. Compostas por diversas seções, relatam as iniciativas do executivo e de seus secretários no que se refere às práticas de governo. Caracterizam-se por conter um texto de apresentação das ações e metas do governo e, na sequência, a descrição sobre os temas: política e economia, com destaque para a produção agrícola e, por sua vez, para a viação e transportes, energia elétrica, imigração e colonização, crédito, política social, saúde pública, saneamento, água e esgotos, educação e cultura, trabalho e assistência social, segurança pública, administração geral, fazenda pública, organização administrativa, edificações públicas, ação legislativa. Em relação à educação, as mensagens apresentam dados provenientes dos relatórios das secretarias estaduais de educação.

Nestes documentos procuramos identificar as ações empreendidas pelos administradores ao deliberarem sobre as questões consideradas essenciais para governar a população do Estado, o papel ocupado pela educação rural e os modelos de escola primária que foram institucionalizados, bem como sua expansão no período em estudo.

As mensagens e relatórios correspondem aos exercícios administrativos dos seguintes presidentes de Estado, governadores e interventores: Afonso Alves de Camargo (1928-1930), Mário Alves Monteiro Tourinho (1930-1931), Manoel Ribas (19311945), Moysés Lupion (1947-1951 e 1956-1961) e Bento Munhoz da Rocha Netto (19511955).

O período em foco foi caracterizado por momentos de grandes modificações no sistema político brasileiro, marcado, ao final de 1930, por um quadro de medidas

7 Conforme Fausto (2003), em agosto de 1931, o chamado Código dos Interventores estabeleceu as normas de subordinação destes ao poder central e, com a instituição do Estado Novo (1937-1945), os governadores dos Estados foram transformados em interventores ou, como na maioria dos casos, substituídos. 
centralizadoras do governo provisório de Getúlio Vargas, dentre elas, a intervenção federal nos Estados. Após a promulgação da Constituição de 1934, quando o país parecia ter retomado o regime democrático, gestou-se o Estado Novo, instituído por Vargas em 1937, dando início a um novo período de medidas intervencionistas, no qual o regime centralizador e autoritário dava ao presidente a possibilidade de governar por meio de decretos leis, suprimindo as liberdades constitucionais (Fausto, 2003). Em 1945, com o fim do Estado Novo e o retorno das instituições democráticas, iniciava-se um novo período de democratização, que perdurou até o golpe de Estado de 1964.

No Paraná, o contexto analisado foi marcado pela ocupação do território, aumento populacional, surgimento dos novos centros urbanos e colonização das áreas rurais; movimento que, não sem conflitos, foi vislumbrado pelas pessoas da época como um período de progresso e modernização, no qual a educação foi enfatizada como um dos fatores desta modernidade.

\section{Povoar e educar: a escola primária rural em foco}

Não há, em todo o Brasil, oportunidade melhor que a hora vivida pelo Paraná em suas zonas rurais, para o início dessa assistência. Ao contrário do que acontece nas maiores áreas nacionais, é insignificante no Paraná o êxodo das populações para as cidades. E o movimento migratório interno, que há tempos se processa no país, talvez o maior que a história nacional registra, está povoando intensamente as nossas melhores terras de lavoura. Os contingentes humanos que procuram ininterruptamente o norte e o noroeste do Estado, a maior faixa continua de terras férteis no Brasil, e as correntes imigratórias que, oriundas do extremo sul, procuram o sudoeste e oeste paranaense, garantem uma prosperidade sem par ao nosso Estado. O Paraná possui, desde 1920, o maior crescimento demográfico do Brasil, está sendo intensamente povoado e trabalhado. Mas essa expansão não se faz sem os dramas do homem rural. É necessário que o poder público venha assisti-lo e, aqui, o pode fazer em condições melhores que na maioria dos Estados brasileiros, evitando-se a formação de problemas complexos no futuro. (Paraná, 1951a, p. 6)

O texto da mensagem apresentada pelo governador Bento Munhoz da Rocha Netto à Assembleia Legislativa do Estado, por ocasião da abertura da sessão legislativa de 1951, evidencia o teor das preocupações que marcaram as vozes dos governantes paranaenses no período delimitado.

Imbuídos do discurso de modernidade, tal como em âmbito federal, os governos de Manoel Ribas, como interventor (1932-1935 e 1937-1945) e governador (1935-1937), Moysés Lupion (1947-1951 e 1956-1961) e Bento Munhoz da Rocha Netto (1951-1955), como governadores, são caracterizados por práticas administrativas voltadas ao povoamento do território, por meio dos trabalhos de colonização das regiões Norte, Oeste e Sudoeste do Estado e da construção de uma malha rodoviária ${ }^{8}$ para integrar as

\footnotetext{
${ }^{8}$ A questão dos transportes foi uma constante nos documentos do período, considerada pelos governantes como "ponto fundamental e nevrálgico da vida administrativa do estado" (Paraná, 1948, p. 7). O plano rodoviário estratégico, iniciado na gestão de Manoel Ribas, foi intensificado nos governos de Lupion e Rocha Netto com a construção de autoestradas para ligar a capital, Curitiba, ao Porto de Paranaguá e às cidades do interior, os centros produtores, permitindo o escoamento e a circulação da produção. Em 1958, as rodovias que estavam concluídas ou em fase de conclusão foram denominadas de acordo com a riqueza em circulação: "Rodovia do Café, Rodovia dos Cereais, Rodovia do Mate, Rodovia do Trigo, Rodovia da Madeira e dos Minérios" (Arquivo Público, 2002, p. 20). 
diferentes regiões e possibilitar a consolidação do Paraná como o maior produtor e exportador de café (Arquivo Público, 2000, 2002): "Povoar o Paraná, mais que um mero ato do Executivo, constitui a verdadeira arte de governar", ressalta o documento do Ipardes (1989, p. 55). Ocupado de forma diversa por diferentes grupos étnicos, por imigrantes europeus e asiáticos e processos de migrações internas, o Paraná ${ }^{9}$ manteve uma forte relação com o mundo rural durante a fase de ocupação de seu território.

Com uma população de 1.235 .849 habitantes na década de 1940 , apenas $24,5 \%$ dos paranaenses residiam na zona urbana. As taxas de urbanização da década de 1950 apontam para índices inferiores da media nacional. Enquanto no Brasil a taxa de urbanização era de $36,1 \%$, no Paraná a mesma taxa era de $25 \%{ }^{10}$. As maiores modificações ocorreriam no decorrer das décadas de sessenta e setenta do século 20 , com o processo de urbanização e o êxodo do trabalhador rural do campo.

\section{Tabela 1}

Dados populacionais, situação de domicílio e taxa de crescimento (Paraná 19401980).

\begin{tabular}{|c|c|c|c|c|}
\hline Ano & Total da população & Área urbana \% & Área rural \% & $\begin{array}{c}\text { Taxa de } \\
\text { crescimento \% }\end{array}$ \\
\hline 1940 & 1.235 .849 & 24,5 & 75,5 & - \\
\hline 1950 & 2.112 .893 & 25,0 & 75,0 & 70,0 \\
\hline 1960 & 4.268 .239 & 30,9 & 69,1 & 102,0 \\
\hline 1970 & 6.929 .868 & 36,4 & 63,6 & 62,0 \\
\hline 1980 & 7.063 .466 & 58,9 & 41,1 & 10,0 \\
\hline
\end{tabular}

Fonte: Elaborada com base em documentos do Ipardes $(1989,1993)$ e IBGE (2010).

Os dados apresentados apontam para uma taxa de crescimento em torno de 70 e 100\% no decorrer das décadas de 1950 e 1960, contexto no qual modernizar o Estado consistia em criar infraestrutura e ofertar serviços públicos básicos para atender à população oriunda do crescimento demográfico, vinculado à "ocupação das terras férteis do norte, sobretudo por mineiros e paulistas, e da região oeste e sudoeste do estado, por gaúchos e catarinenses" (Arquivo Público, 2002, p. 18), além dos fluxos migratórios oriundos do exterior. Como parte destas medidas, foram criadas a Divisão de Imigração, junto a Secretaria de Agricultura, a Fundação Paranaense de Imigração e Colonização ${ }^{11}$

\footnotetext{
${ }^{9}$ Foi somente a partir dos anos de 1960 que o estado pode ser considerado territorialmente ocupado. Segundo o modelo explicativo de Wachowicz (2010) e Balhama, Pinheiro Machado e Westphalen (1969), a ocupação do território pode ser dividida em três áreas histórico-culturais: o Paraná Tradicional, ocupado inicialmente por portugueses, negros e índios e, a partir do século XIX, por imigrantes de diferentes grupos étnicos; a região norte foi colonizada, inicialmente, por mineiros e paulistas e, posteriormente, por imigrantes japoneses e italianos, tendo a partir dos anos de 1930 seu processo de colonização dirigido por companhias privadas. $\mathrm{E}$ a terceira área formada pela região sudoeste e oeste do estado, iniciada no final dos anos 1920 e intensificada no decorrer da década de 1950, colonizada por correntes migratórias oriundas do Rio Grande do Sul e Santa Catarina. O povoamento intensivo dessas duas regiões resultou da colonização com elementos nacionais, por intermédio da iniciativa dos governos federal e estadual, mas, sobretudo, de atividades colonizadoras realizadas por empresas particulares.

10 Documentos: Oliveira (2001); Ipardes (1989).

11 Segundo Magalhães (2001, p. 59), as companhias particulares ainda detinham, durante a década de 1930, o controle das iniciativas de colonização, "sendo responsabilizadas por abusos contra seus colonos". Neste sentido, o Governo do Paraná, por meio desses órgãos, "passa a ter condições de atuar no sentido de estabelecer infra-estrutura básica capaz de propiciar o bem-estar da população que para lá se dirigia".
} 
em 1947, a Fundação de Assistência ao Trabalhador Rural em 1951 e o Departamento Administrativo do Oeste do Paraná, posteriormente denominado Departamento de Fronteira (Magalhães, 2001; Arquivo Público, 2002).

Em relação ao movimento de colonização do Paraná é importante observar que o mesmo não ocorreu de forma pacífica, mas resultou em graves conflitos de terras motivados pela especulação financeira e pela grilagem, impondo a necessidade de criação da Chefatura de Polícia, a partir do desmembramento da Secretaria do Interior, Justiça e Segurança Pública em 1948.

"Embora os relatórios de governo apontassem para a tranquilidade social" (Arquivo Público, 2002, p. 19), isso pode ser observado quanto ao processo de ocupação ${ }^{12}$ das terras do então chamado Norte Novo e Novíssimo paranaense pela Companhia de Terras Norte do Paraná - CTNP ${ }^{13}$. No momento em que a CTNP articulou a colonização, o território não era inóspito e nem desabitado, havia a presença de caboclos e índios, como assinalam Cancian (1981) e Hoff (1991). A própria companhia "confirma a presença desses caboclos, dizendo que todos foram indenizados para saírem das terras" (Hoff, 1991, p. 27), sugerindo o processo de expulsão destas populações, mesmo que pela via da indenização.

A colonização e urbanização das terras foram marcadas pelo planejamento urbano e rural. A Companhia, ao implantar os núcleos urbanos, seus patrimônios, distritos e sedes de comarcas, desenhava, concomitantemente, o mesmo traçado planejado para a área rural:

O posicionamento das cidades de maior relevância acompanhava a linha férrea ou as estradas de rodagem, o percurso da linha férrea coincidia com as linhas naturais dos divisores de águas e as estradas que conduziam às propriedades rurais também adotavam o mesmo posicionamento. Para tornar o espaço habitável e comercializável, o território desbravado foi dividido em pequenas propriedades delimitadas de um lado pelo curso d'água e de outro pela via de acesso, sempre cumeadas, de modo a prover cada lote rural de fácil acesso à água e ao transporte. (Meneguetti, 2009, p. 77)

Apesar deste traçado não configurar a totalidade das áreas rurais do Estado, observa-se sua relevância associada às ações do Estado no sentido de por em prática políticas de colonização, urbanização e organização do meio rural. Neste contexto, a escola primária rural foi estruturada como uma política estadual por dois fatores: o primeiro relacionado à formação das novas gerações que pudessem garantir a riqueza do Estado e o segundo civilizar a população que habitava no meio rural, ensinar não só a ler, escrever e contar, mas hábitos de higiene e valorização da vida no campo. Manter o

\footnotetext{
${ }^{12}$ Mota e Noelli (1999, p. 50) observam que é importante relembrar que os territórios entre os rios Tibaji, Ivaí e Piquiri, onde estão assentadas as modernas cidades paranaenses, como Londrina, Maringá, Campo Mourão, Umuarama, Cascavel e centenas de outras, menores, nunca estiveram vazios desde a sua humanização - chegada dos primeiros homens - há mais de dez mil anos. Também não eram "sertões desconhecidos" como quer fazer acreditar certa historiografia. Desde o século XI, existem relatos sobre a região e seus habitantes indígenas. Tomazi (1999, p. 58) apresenta dados relevantes sobre o número de propriedades rurais existentes na década de 1920, anteriores ao período de (re) ocupação das terras do norte do Estado.

${ }^{13}$ Posteriormente denominada Companhia Melhoramentos Norte do Paraná - CMNP. Em finais da década de 1950, a Companhia havia loteado uma área total de 544.017 alqueires distribuídos em 41.741 lotes rurais e quase 70 mil datas urbanas (CMNP, 1975, p. 53). 
homem do campo no campo, mas em condições de tornar o campo moderno, de modo a implantar a economia associada ao rural.

Qual modelo ou modelos coexistiram com as escolas urbanas responsáveis por escolarizar a população citadina do Estado? Os documentos permitiram constatar alguns modelos de escolas primárias no meio rural paranaense, dentre eles: as escolas de trabalhadores rurais e de pescadores, subordinadas ao Departamento de Agricultura, da Secretaria de Obras Públicas, Viação e Agricultura - Seção de Ensino Profissional e, posteriormente, ao Departamento de Ensino Superior, Técnico e Profissional, vinculado a Secretaria de Agricultura do Estado; o grupo escolar rural e a escola primária rural, modelo de escola isolada que atendia às populações rurais, também denominadas nos documentos como Casa Escolar Rural. Estas últimas estiveram subordinadas a Secretaria do Interior, Justiça e Instrução Pública e, posteriormente, a Secretaria de Estado da Educação e Cultura.

Focalizaremos os modelos de escola primária rural, vinculados às Secretarias de Instrução Pública e Educação e Cultura e seu processo de expansão no quadro geral do Estado.

\section{Da escola isolada da zona rural ao grupo escolar rural: os diferentes modelos de escola primária}

A denominação Escola Primária Rural foi apresentada, pela primeira vez, em mensagem referente ao exercício nos anos de 1924 a 1928 e apresentada, pelo presidente de Estado, Caetano Munhoz da Rocha, ao Congresso Legislativo, indicando as 120 escolas primárias rurais subvencionadas pela União ${ }^{14}$, em conformidade com 0 decreto n. 13.014, de 13 de maio de 1918 (Paraná, 1928). Sobre esta questão é interessante observar as prescrições da Reforma João Luíz Alves da Rocha Vaz, instituída pelo decreto n. 16.782A, de 13 de janeiro de 1925, que estabelecia a participação da União para a difusão do ensino primário, bem como criava as bases sobre as quais a União subvencionaria os Estados na difusão da escola primária rural:

Art. 25. Os acordos obedecerão a ás seguintes bases: a) a União obriga-se a pagar diretamente os vencimentos dos professores primários, até 0 máximo de 2:400\$ anuais, e os Estados a fornecer-lhes casa para residência e escola, assim como o necessário material escolar; b) as escolas subvencionadas serão de natureza rural. (Brasil, 1925, p. 27)

O decreto obrigava os Estados a não reduzirem o número de escolas existentes e a aplicarem $10 \%$ de sua receita na instrução primária e normal, permitindo que a União fiscalizasse o funcionamento das escolas por ela subvencionadas e fornecesse o programa a ser adotado. Na análise de Cury (2007, p. 834), a reforma Rocha Vaz exemplifica a forma como a União, após a Constituição liberal de 1891, financiava a educação: "de modo pontual e precário em ordenamentos jurídicos negociados com os estados" (p. 834).

\footnotetext{
${ }^{14}$ O decreto federal n. 13.014, de 04 de maio de 1918, regula o auxílio financeiro por parte do Governo Federal, mediante a concessão de 1:800\$ anuais, para manutenção de cada escola fundada pelos governos dos Estados, destinadas ao ensino da língua portuguesa, da geografia e história do Brasil, em municípios constituídos por antigas colônias de europeus (Brasil, 1919, p. 6037).
} 
Essa escola primária rural, subvencionada mediante acordo com o governo federal, situava-se, sobretudo, nas zonas de colonização e configurava-se como escolas isoladas, regidas por um único professor, em salas multisseriadas. Em relatório referente ao exercício de 1932 a 1939, o interventor Manoel Ribas, ao apresentar os dados sobre a expansão do ensino primário, informou a existência de 254 escolas primárias rurais subvencionadas pelo governo federal, 71 grupos escolares e 1.288 escolas isoladas, o que indica a predominância deste último modelo de escola na oferta do ensino primário (Paraná, 1939).

Sobre as escolas isoladas no Paraná, apesar de não termos dados precisos, podemos considerar que uma parte significativa estava instalada na zona rural, tendo em vista que a maior parte da população se concentrava no campo. No entanto, os relatórios e as mensagens dos governadores e interventores não especificam, nos quadros gerais da expansão do ensino, quantas destas escolas isoladas estavam delimitadas ao meio rural e urbano. Ao longo do período os documentos atribuem a denominação rural àquelas escolas subvencionadas, ora mediante acordo com o governo federal, ora mediante acordo entre o Estado e os municípios, ora financiadas pelo próprio Estado.

Com a ditadura do Estado Novo (1937-1945) em curso e tendo a Constituição de 1937 retirado a vinculação constitucional de recursos para a educação (Cury, 2007), a União manteve a sua ação supletiva na construção e manutenção de escolas primárias e profissionais, "destinadas ao preparo de trabalhadores para as atividades agrícolas" (Brasil, 1937, art. 116), nas zonas rurais de todo país, em conformidade com a lei n. 378, em 13 de janeiro de $1937^{15}$.

Essa ação supletiva pode ser identificada no Paraná por meio da construção de 22 grupos escolares rurais durante o governo de Manoel Ribas. Em relatório referente ao período de 1940 a 1941, o governador registra a construção dos grupos escolares rurais circunscritos ao que denomina de "grande plano do governo do Estado", desenvolvido com o apoio do governo federal, por intermédio do Ministério da Educação e Saúde, para construção de escolas nas principais zonas colonizadas do Estado, mediante auxílio financeiro de $\mathrm{R} \$$ 3.500:000\$000 (Paraná, 1941, p. 28A).

O grupo escolar rural foi um dos modelos de escola primária responsável por escolarizar a população que residia nas áreas rurais do Estado. No quadro seguinte estão expostos os dados sobre as localidades dos grupos escolares rurais construídos e em construção, por conta do auxílio federal, nos diferentes municípios do Estado.

Quadro 2

Grupos escolares rurais construídos e em construção (1940-1941).

\begin{tabular}{|c|c|c|c|}
\hline Modelo & Localidade & Número de salas & Observação \\
\hline Grupo escolar rural & Cornélio Procópio & 8 salas & Concluído \\
\hline Grupo escolar rural & Teixeira Soares & 8 salas & Concluído \\
\hline Grupo escolar rural & Marechal Malé & 8 salas & Concluído \\
\hline Grupo escolar rural & Bandeirantes & 6 salas e residência & Concluído \\
\hline Grupo escolar rural & Cruz Machado & 4 salas e residência & Concluído \\
\hline Grupo escolar rural & Vera Guarani & 2 salas e residência & Concluído \\
\hline
\end{tabular}

\footnotetext{
${ }^{15}$ Lei n. 378, de 13 de janeiro de 1937. Dá nova organização ao Ministério da Educação e Saúde Pública, assinada por Getúlio Vargas, Gustavo Capanema e Arthur de Souza Costa. 


\begin{tabular}{|c|c|c|c|}
\hline Grupo escolar rural & Afonso Pena & 2 salas e residência & Concluído \\
\hline Grupo escolar rural & Santa Bárbara & 2 salas e residência & Concluído \\
\hline Grupo escolar rural & Dorizon & 2 salas e residência & Em andamento \\
\hline Grupo escolar rural & Valinhos & 2 salas e residência & Em andamento \\
\hline Grupo escolar rural & Rio Azul & 6 salas & Em andamento \\
\hline Grupo escolar rural & São Mateus & 8 salas & Em andamento \\
\hline Grupo escolar rural & Guarapuava & 8 salas & Em andamento \\
\hline Grupo escolar rural & Palmas & 8 salas & Em andamento \\
\hline Grupo escolar rural & Ingá & 6 salas & Em andamento \\
\hline Grupo escolar rural & Bom Jardim & 4 salas & Em andamento \\
\hline Grupo escolar rural & Cerro Azul & 4 salas & Em andamento \\
\hline Grupo escolar rural & Porto Vitória & 2 salas e residência & Em andamento \\
\hline Grupo escolar rural & Pato Branco & 2 salas e residência & Em andamento \\
\hline Grupo escolar rural & Três Bicos & 2 salas e internato & Em andamento \\
\hline Grupo escolar rural & Laranjeiras & 2 salas e internato & Em andamento \\
\hline
\end{tabular}

Fonte: Relatório 1940-1941 (Paraná, 1941).

Os grupos escolares rurais construídos com recursos do governo federal obedeceram a um padrão de edificação: em alvenaria, entre duas a oito salas de aula, com ou sem residência para professor. O padrão da construção pode ser observado na foto do Grupo Escolar Rural de Bandeirantes, município situado na região Norte do Estado, uma das escolas edificadas mediante auxílio concedido pelo Ministério da Educação e Saúde, obra concluída no valor de R\$199:328\$000 (Paraná, 1941).

Imagem 1

Grupo Escolar Rural de Bandeirantes-PR.

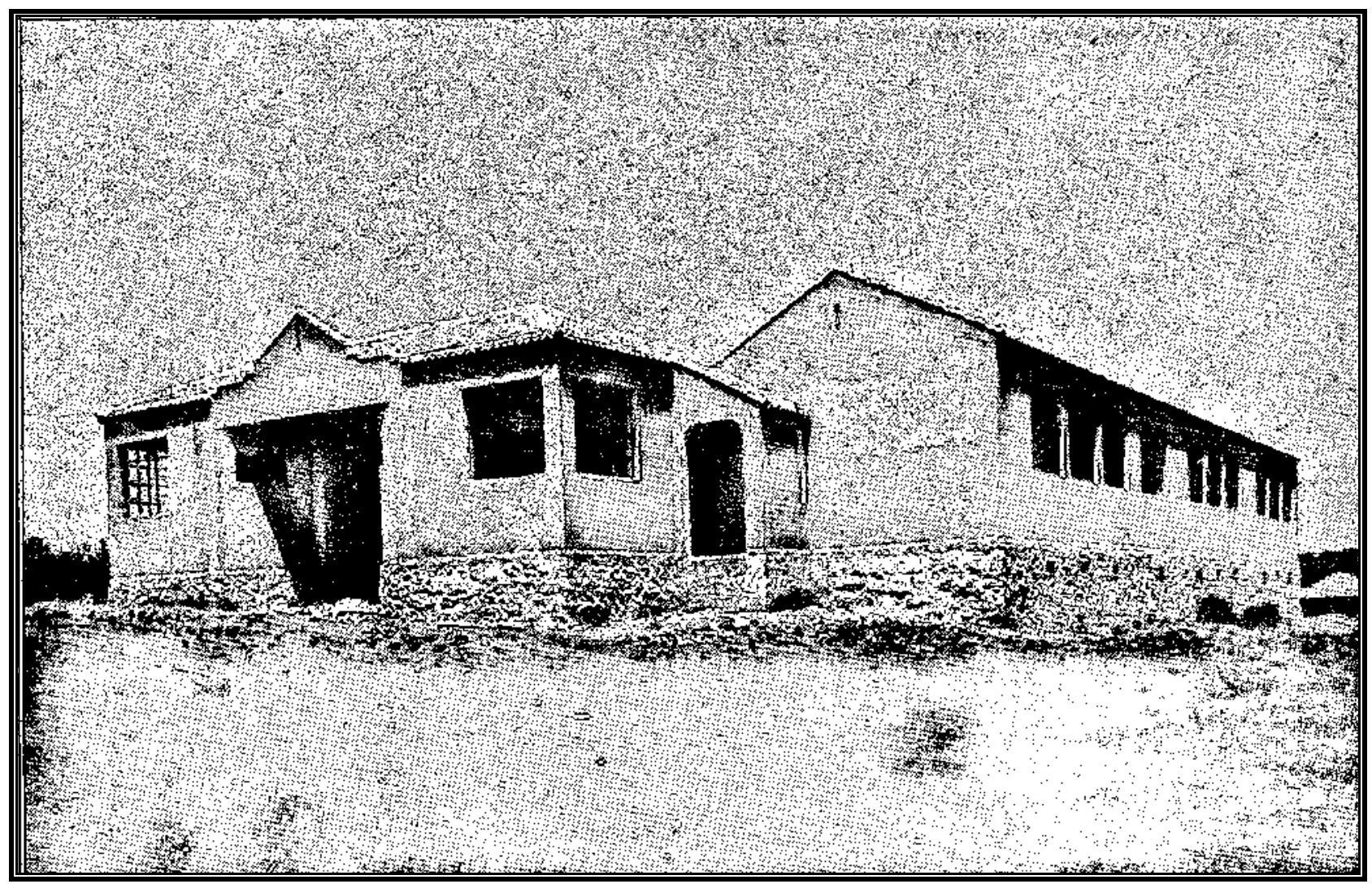

Fonte: Relatório 1940-1941 (Paraná, 1941). 
Com o fim do Estado Novo e o retorno ao regime democrático, a questão da educação rural ganhou ênfase no cenário educacional, sobretudo diante dos dados sobre a realidade do ensino primário no Brasil, evidenciados pelo Instituto Nacional de Estudos Pedagógicos - Inep - quanto ao número insuficiente de escolas para o atendimento das crianças em idade escolar, sobretudo de escolas rurais. Para tanto, destaca Ávila (2013,) o Inep criou o Programa de Organização do Ensino Primário, incluindo a construção de escolas primárias adequadas à zona rural e o treinamento de professores. A edificação destas escolas acontecia com base no convênio firmado com os Estados, por meio do qual "o Inep transferia ao órgão educacional competente, de sua conta do Banco do Brasil, os créditos necessários para a construção de escolas nas zonas rurais, de fronteira e colonização" (Ávila, 2013, p. 139).

Ao que indicam os dados do relatório sobre a concretização do plano de obras do governo Moysés Lupion, referente ao período de 1947 a 1950, as trinta casas escolares rurais construídas nas regiões Norte e Sudoeste do Paraná, principais núcleos de colonização na época, correspondem ao convênio firmado entre o Inep e os Estados (Paraná, 1950).

A construção das casas escolares rurais recebeu destaque no relatório sobre a concretização do plano de obras do governo Moysés Lupion, no qual foi exposto o quadro das edificações escolares situadas nos núcleos coloniais, "onde não havia possibilidade das Prefeituras e das populações construírem casas escolares, o Governo realizou essa obra de assistência, construindo casas escolares para que, as crianças, não ficassem relegadas ao abandono" (Paraná, 1950, p. 370).

Quadro 3

Quadro de edificações das casas escolares rurais (1947-1950).

\begin{tabular}{|l|c|c|c|c|}
\hline \multicolumn{1}{|c|}{ Localidade } & Natureza da obra & Construídas & $\begin{array}{c}\text { Em } \\
\text { construção }\end{array}$ & Planejadas \\
\hline $\begin{array}{l}\text { Abatiá, em Água das } \\
\text { Pedras }\end{array}$ & madeira & & 1 & 1 \\
\hline Andirá, em Moacyr Correia & & & & 1 \\
\hline Assaí, em Saltinho & & & & 1 \\
\hline Bela Vista do Paraíso & & & & 1 \\
\hline Cambará & madeira & 1 & & 1 \\
\hline Cambé, em Saltinho & & & & \\
\hline $\begin{array}{l}\text { Cambé, Fazenda Santa } \\
\text { Cândida }\end{array}$ & & & & \\
\hline Carlópolis & madeira, com 1 sala & 7 & & \\
\hline Clevelândia - região Oeste & madeira, com 1 sala & 8 & & \\
\hline $\begin{array}{l}\text { Foz do lguaçu - região } \\
\text { Oeste }\end{array}$ & madeira, com 1 sala & 10 & & \\
\hline $\begin{array}{l}\text { Laranjeiras do Sul - região } \\
\text { Oeste }\end{array}$ & madeira, com 1 sala & 4 & 12 & \\
\hline $\begin{array}{l}\text { Mangueirinha - região } \\
\text { Oeste }\end{array}$ & & 30 & 13 & \\
\hline Total & & & & \\
\hline
\end{tabular}

Fonte: Relatório 1947-1950 (Paraná, 1950).

O relatório apresentado ao governador Bento Munhoz da Rocha Netto, pelo diretor do Departamento Administrativo do Oeste do Paraná, Estevam Ribeiro de Souza Netto, 
em 1951, refere-se à edificação de casas escolares rurais do convênio federal, mediante contrato com o Ministério da Educação e Cultura, nas áreas rurais das seguintes localidades: Caremã, perto das Cataratas, Santa Helena, Rio das Antas, estrada Cascavel-Toledo, Santa Tereza, estrada Cascavel-Foz do Iguaçu, Sanga Funda, estrada velha para Cascavel, Santa Terezinha, a $18 \mathrm{~km}$ de Foz do Iguaçu, Salto, estrada Cascavel-Catanduvas, e Santa Cruz, estrada Cascavel-Piquiri (Paraná, 1951b).

A imagem a seguir retrata o tipo padrão de casa escolar rural, com uma sala de aula, edificada em madeira na área rural dos municípios de Foz do Iguaçu, Laranjeiras do Sul, Mangueirinha e Clevelândia, situados na região Oeste do Estado (Paraná, 1950; 1951b).

\section{Imagem 2}

Casa Escola Rural, Foz do Iguaçu-PR.
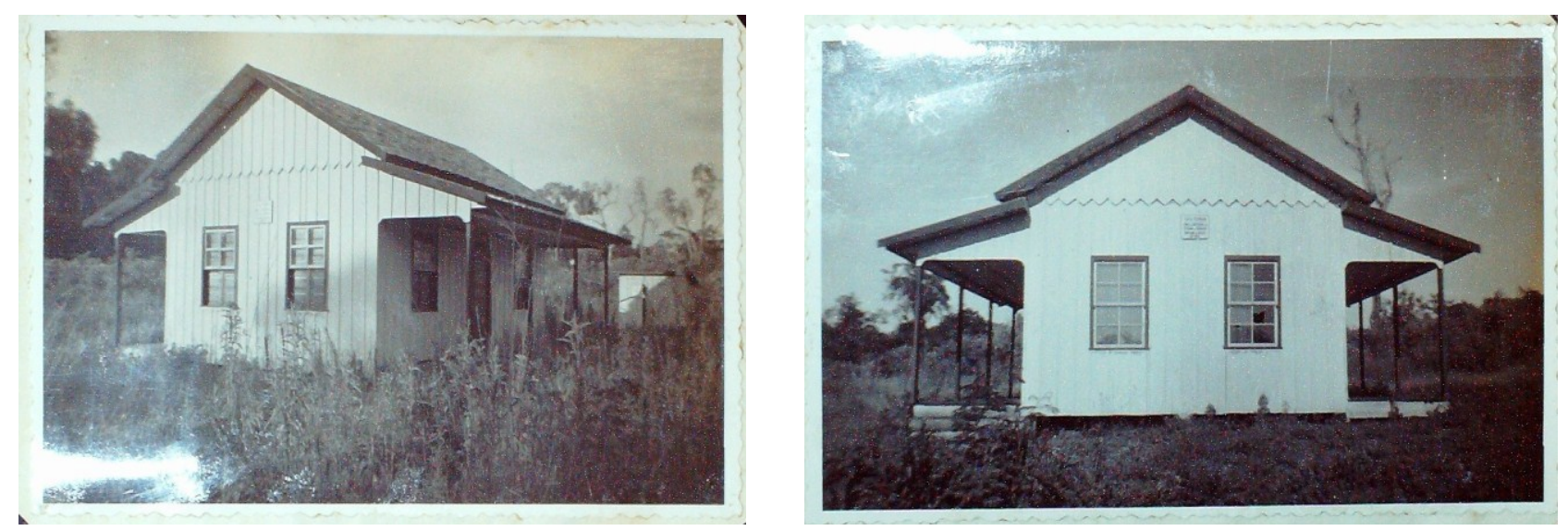

Fonte: Relatório (Paraná, 1951b).

Ao iniciar a década de 1950, a mensagem de abertura da sessão legislativa de Lupion reflete a tônica do Programa de Organização do Ensino Primário. Ao dar ênfase ao fato de que o Paraná representava o maior centro agrícola do país e que, se ainda não o fosse, o Estado marchava rapidamente para isso, o governador afirmava as ações de seu governo relacionadas à educação primária, à formação de professores e, sobretudo, ao ensino rural. Dentre elas, estava o plano de aumento e ampliação da rede de ensino primário rural, em regime de acordo com os municípios, mediante o qual o Estado assumia a responsabilidade financeira pela abertura de escolas na zona rural, pagando os professores, dotando-as de material e assistindo-as tecnicamente (Paraná, 1950).

Os dados apresentados no relatório indicam terem sido abertas cerca de 500 novas escolas na zona rural durante o ano de 1949. Para o ano de 1950 estimava-se a abertura de 1.200 unidades. O governador destacava o atendimento de quinze mil crianças beneficiadas com o plano de ampliação da rede escolar rural do Estado e enfatiza a batalha empreendida em relação à matrícula e frequência nas escolas rurais (Paraná, 1950).

Como medida paliativa, que denominou de "incipiente formação da maioria do nosso professorado dessas escolas" (Paraná, 1950, p. 30), distribuiu um total de 25.000 cartilhas "com o objetivo de comunicar-Ihes técnica muito simples para o ensino fundamental da 
leitura, da escrita e do cálculo do $1^{\circ}$. ano, e para que elas alcancem fazer a sua escola mais agradável e mais profundamente educativa" (Paraná, 1950, p. 30).

Afirmava, ainda, que uma das batalhas travadas para a melhoria no rendimento das escolas do meio rural foi sua decisão de organizar cursos de formação para as professoras das escolas isoladas da zona rural:

Esses cursos foram assistidos em todo o Estado por mais de 1.000 professoras, e foram ministrados nas sedes dos municípios pelos inspetores de ensino, segundo um plano que estes aprenderam, por sua vez, em cursos, nas sedes das regiões, lecionados pelo próprio Secretário da Educação e Cultura. Temos a convicção plena de que tais cursos darão, para o ano de 50, os melhores resultados em rendimento de nossas escolas rurais, pelos índices de aproveitamento manifestados pelos professores que os cursaram. (Paraná, 1950, p. 30)

O governador põe em evidência, ainda, a criação de escolas normais regionais como medida substancial e de maior alcance, no sentido de dar solução ao problema da escola isolada rural, com a formação do mestre rural na própria região onde residia, uma das grandes tematizações da época no tocante à escola primária rural (Hall, 1950; Mennucci, 1934, Pilotto, 1952). A mensagem relata a criação de dezenove cursos normais regionais, instituídos a partir da Lei Orgânica do Ensino Normal de 1946:

A mais profunda das medidas de nossa administração no setor do ensino primário, destinada a dar ao problema que assim se enfrenta uma solução definitiva dentro dos próximos anos. De par com a sua criação, baixamos os programas respectivos, que são uma verdadeira orientação para a sua vida e o seu espírito e, nesse sentido, talvez tenhamos nos adiantado alguma coisa sobre o que de melhor possa estar feito no Brasil. (Paraná, 1950, p. 31)

A aproximação entre a população e a escola rural, com o objetivo de influir sobre as populações adultas das zonas rurais e de receber, por sua vez, o benefício de sua influência, levou o Estado a promover a criação dos Centros de Amigos da Escola em torno das escolas isoladas rurais. A mensagem relata a existência de 249 centros em funcionamento em 1950 (Paraná, 1950).

Quanto à educação da criança da zona rural, o relatório afirma ser este um dos pontos mais críticos da atividade educacional pública, à medida que "a criança da zona rural é, inquestionavelmente, das que mais precisam de uma profunda influência criadora da escola, e, infelizmente, a escola da zona rural é a mais deficiente de todo o nosso sistema" (Paraná, 1950, p. 143).

Ao ressaltar o crescimento vertiginoso do Estado, em virtude dos movimentos migratórios, e constatar que o sistema educacional não acompanhou esse crescimento, Lupion enfatizava os esforços de sua gestão para suprir o déficit de escolas na zona rural, mediante acordo com os municípios para fornecer auxílio financeiro para a abertura de novas escolas e manutenção da assistência de material e técnica necessária. Com essa iniciativa afirmava que "estamos desse modo, satisfazendo a uma das solicitações mais vivas que encontramos sempre na alma do povo: a escola. Na verdade, para felicidade nossa, a escola vem cada vez mais se incrustando na consciência do povo" (Paraná, 1950, p. 144). 
Em relação à formação de professores, Lupion relatava a oferta dos chamados Cursos de Experiência, que objetivavam "superar as aulas do abc, do ler, escrever e contar, que restringiam o aluno da escola rural ao alfabetizar-se" (Paraná, 1950, p. 144). A ideia dos cursos era introduzir certas atividades que estivessem de acordo com os impulsos das crianças, com as necessidades da vida infantil, capazes de colocar em movimento as forças criadoras do espírito da criança, satisfazendo necessidades biológicas do desenvolvimento infantil, introduzindo mais alegria na escola, "fazendo a escola mais educativa pela força de ativar as forças criadoras do espírito, enriquecendo, assim, a vida, pensamos, dizíamos, que a introdução de atividades muito simples, dessa natureza, deveria ser o segundo dos objetivos da nossa imediata atenção" (Paraná, 1950, p. 147). Por fim, a mensagem cita Missões Culturais na zona rural, como parte do esforço que sua administração em benefício da criança e da educação rural no Paraná.

A questão educação rural continuou a ser a tônica do Estado no decorrer da década de 1950, em sintonia com os debates nacionais que culminaram com a aprovação do Plano da Campanha de Educação Rural ${ }^{16}$, em dezembro de 1951, pelo ministro da Educação e Saúde, Ernesto Simões Filho.

Lupion, em seu segundo mandato como governador do Paraná, momento em que a cultura do café assumiu importância para a economia do Estado ao atingir uma safra aproximada de 10 a 12 milhões de sacas, o que o colocava como líder da produção cafeeira do país, destacava as metas a serem atingidas até 1960: construção de mais 1.000 casas escolares rurais, aumento do número de professores primários, criação de 80 cursos normais regionais, em sua maioria fundados nas principais zonas de colonização do Estado: as regiões Norte, Oeste e Sudoeste (Paraná, 1958).

\section{Considerações finais}

Nas delimitações desta pesquisa consideramos que a emergência da institucionalização e da expansão da escola primária rural, ofertada nos grupos escolares rurais, nas escolas primárias rurais subvencionadas pela União ou mesmo nas escolas isoladas das áreas rurais, também denominadas Casas Escolares Rurais, acompanhou o processo de povoamento e de desenvolvimento econômico do Estado.

Nas mensagens e relatórios de governo foi possível acompanhar os relatos sobre os processos de colonização, a expansão da malha rodoviária e ferroviária, a instalação dos municípios e a criação de escolas de forma concomitante. O potencial agrícola do Paraná, o forte impulso migratório decorrente da cultura do café na região Norte e da pecuária na região Oeste e Sudoeste, nos fizeram refletir sobre as particularidades do Estado em relação ao país e, internamente, em suas regiões.

A urgência com a educação primária para a infância se tornava primordial diante do alto número de analfabetos que vivia nas áreas rurais. Embora houvesse nas cidades um crescimento da oferta educacional, a elitização do ensino urbano, com a criação os grupos escolares, dificultava o acesso das classes populares ao introduzir a frequência obrigatória, o uniforme e o uso de materiais pedagógicos. A frequência irregular da criança trabalhadora seria inconcebível e o espaço escolar estaria cada vez mais distante da criança da zona rural que participava dos trabalhos, especialmente em tempos de

${ }^{16}$ O primeiro regulamento da CNER foi aprovado em 1952. Sobre a CNER consultar os trabalhos de Barreiro (2010) e Ávila (2013). 
colheita. Isso levou o governo estadual a intervir, de forma estratégica, na oferta do ensino primário no meio rural, conforme relatamos anteriormente.

A questão da escola primária rural e seus mestres produziu mobilização do Estado em torno da formação de professores. Dentre as várias medidas, a expansão do número de escolas normais regionais, voltadas à formação do professor para o meio rural, recebeu destaque. Em trabalho anterior (Hervatini; Schelbauer, 2012), observamos que no Programa para as Escolas Normais Regionais, desenvolvido pelo secretário da Educação Erasmo Pilotto em 1952, salienta-se que uma das finalidades do curso era formar o professor-regente para que, ao conhecer as dificuldades da população local, pudesse fazer da escola "um centro de vida social e educativo de tôda a comunidade" ( $p$. 48), no qual professor atuaria em conjunto com os pais, orientando-os no cumprimento de suas responsabilidades com os filhos. Assim, o programa de ensino das escolas normais regionais deveria estar vinculado à formação da personalidade do professor para, ao alargar sua cultura, destinar a sua ação a objetivos assistenciais junto à comunidade, fosse ela rural ou urbana (Pilloto, 1952).

Concluímos que a relevância deste estudo para a área de História da Educação deve-se à importância da discussão da temática da escola pública primária da zona rural em um período histórico em que o grande contingente da infância brasileira vivia no mundo rural, bem como pela quantidade ainda escassa de produção na área, que suscita a necessidade interlocução e debate em perspectiva comparada.

Cabe salientar que os diversos sentidos atribuídos à educação rural nos tempos e espaços históricos fazem-nos colocar a discussão que ora apresentamos se não em perspectiva da história comparada, por não ter sido este o foco do trabalho, ao menos com a preocupação de suscitar questões que permitam a comparação no âmbito da história da educação brasileira, mais especificamente, da história da escola primária situada no meio rural.

\section{Referências}

MIGUEL, Maria Elisabeth Blanck. A formação do professor para as escolas rurais e as políticas de educação do homem do campo. In: WERLE, Flávia O. C. (org.). Educação rural: práticas civilizadoras e institucionalização da formação de professores. São Leopoldo: Oikos; Brasília: Líber livros, 2010, p. 74-90.

ARQUIVO PÚBLICO. História administrativa do Paraná (1853-1947): criação, competências e alterações das unidades administrativas da Província e do Estado. Curitiba: Imprensa Oficial/Deap, 2000.

ARQUIVO PÚBLICO. História administrativa do Paraná (1948-1998): criação, competências e alterações das unidades administrativas do Estado. Curitiba: Imprensa Oficial/Deap, 2002.

ÁVILA, Virgínia Pereira da Silva de. História do ensino primário rural em São Paulo e Santa Catarina (1921-1952): uma abordagem comparada. Araraquara: Unesp, 2013. $216 f$. Tese (doutorado em Educação). Universidade Estadual Paulista Júlio de Mesquita Filho.

BALHANA, Altiva; PINHEIRO MACHADO, Brasil; WESTPHALEN, Cecília Maria. História do Paraná. 2. ed. Curitiba: Grafipar, 1969.

BAREIRO, Edson. Políticas educacionais e escolas rurais no Paraná 1930-2005. Maringá: UEM, 2007. 107f. Dissertação (mestrado em Educação para Ciência). Programa de Pós- 
Graduação em Educação para a Ciência e o Ensino de Matemática, Universidade Estadual de Maringá.

BARREIRO, Iraíde Marques de Freitas. Política de educação no campo para além da alfabetização (1952-1963). São Paulo: Cultura Acadêmica, 2010.

BRASIL. Decreto n. 16.782, de 13 de janeiro de 1925. Reforma João Luíz Alves da Rocha Vaz. In: BRASIL. Coleção de Leis do Brasil, Câmara dos Deputados. 1925, p. 20, v. 2.

BRASIL. Lei n. 378, de 13 de janeiro de 1937. Dá nova, organização ao Ministério da Educação e Saúde Pública. Rio de Janeiro, 1937. Disponível em: <http://www6.senado.gov.br/legislacao/ListaPublicacoes.action ?id=102716>. Acesso em: 12 dez. 2012.

BRASIL. Decreto federal n. 13.014, de 4 de maio de 1918. Diário Oficial. Estados Unidos do Brasil. República Federal. Ano LVIII - 31ํ. da República - N. 100. Capital Federal, 4 de maio de 1919. Disponível em: <http://www.jusbrasil.com.br/diarios/1772459/dou-secao-104-05-1919-pg-1/pdfView>. Acesso em: 10 jan. 2013.

CAINELLI, Marlene Rosa. Entre a roça e o ditado: a Campanha Nacional de Educação Rural Londrina 1952/1963. Curitiba: UFPR, 1994. 140f. Dissertação (mestrado em História). Programa de Pós-Graduação em História, Universidade Federal do Paraná.

CANCIAN, Nadir Aparecida. Cafeicultura paranaense 1900/1970. Curitiba: Grafipar, 1981.

CAPELO, Maria Regina Clivati. Educação, escola e diversidade cultural no meio rural de Londrina: quando o presente reconta o passado. Campinas: Unicamp, 2000. 298f. Tese (doutorado em Educação). Faculdade de Educação, Universidade Estadual de Campinas.

CAPELO, Maria Regina Clivati. Papéis sociais cruzados: memórias e representações de professoras rurais. Revista Múltiplas Leituras, v. 1, n. 1, 2008, p. 44-65.

COMPANHIA MELHORAMENTOS NORTE DO PARANÁ. Colonização e desenvolvimento do norte do Paraná. São Paulo: CMNP, 1975.

CURY, Jamil. Estado e políticas de financiamento em educação. Educação e Sociedade, v. 28, n. 100,2007, p. $831-855$.

DAMASCENO, Maria; BESERRA, Bernadete. Estudos sobre educação rural no Brasil: estado da arte e perspectivas. Educação e Pesquisa, v. 30, n. 1, 2004, p. 79-89.

FAUSTO, Boris. História do Brasil. São Paulo: USP, 2003.

GAUTHIER Pierre-Louis; LUGINBÜHL, Odile (coord.). Dossier éducation et ruralités. Revue Internationale d'Éducation, Sèvres, n. 59, 2012, p. 1-146.

GRAÇA FILHO, Afonso de Alencastro. História, região e globalização. Belo Horizonte: Autêntica, 2009.

HALL, Robert King. Problemas de educação rural. Rio de Janeiro: Instituto Nacional de Estudos Pedagógicos, 1950.

HERVATINI, Luciana; SCHELBAUER, Analete Regina. A escola normal regional no interior do Paraná: a realidade e a idealidade de suas práticas pedagógicas. Revista HISTEDBR On-line., v. 12, n. 45, 2012, p. 296-309. Disponível em: <http://www.fae.unicamp.br/revista/index.php/ histedbr/issue/view/224>. Acesso em 10 jan., 2012.

HOFF, Sandino. A ocupação do norte. In: PAZ, Francisco (org.). Cenários de economia e política - Paraná. Curitiba: Prephacio, 1991, p. 25-39. 
IBGE. Sinopse do Censo Demográfico 1960, 1970, 1980, 1991, 2000 e 2010. Brasil, 2010. Disponível em: <http://www.censo2010.ibge.gov.br/sinopse/ index.php?dados=9\&uf=00>. Acesso em 15 dez., 2012.

IPARDES. O Paraná reinventado: política e governo. Curitiba: Ipardes, 1989.

IPARDES. Séries retrospectivas do Paraná: dados históricos da indústria (1940-1980). Curitiba: Ipardes, 1993.

LE GOFF, Jacques. História e memória. Campinas: Unicamp, 2012.

MAGALHÃES, Marion Brepohl de. Paraná: política e governo. Curitiba: Seed, 2001.

MARQUES, Vera Regina Beltrão Marques; FARIAS, Fabiana Costa de Senna Ávila. Façamos dessa gente um elemento seguro do nosso progresso material e moral: a inspeção médico-escolar no Paraná dos anos 1920. Educação em Revista, v. 26, n. 1, 2010, p. 287-302.

MARTINIAK, Vera Lucia. Processo histórico de institucionalização das primeiras escolas agrícolas nos Campos Gerais, PR. Campinas: Unicamp, 2011. 129f. Tese (doutorado em Educação). Faculdade de Educação, Universidade Estadual de Campinas.

MENEGUETTI, Karin Schwabe. Cidade jardim, cidade sustentável: a estrutura ecológica urbana e a cidade de Maringá. Maringá: UEM, 2009.

MENNUCCI, Sud. (1934). A crise brasileira de educação. Versão para eBook. eBooksbrasil. Fonte digital. Digitalização da 2. edição em papel de 1934. São Paulo: Piratininga, 1934.

MIGUEL, Maria Elisabeth Blanck. As escolas rurais e a formação de professores: a experiência do Paraná 1946-1961. In: WERLE, Flávia Obino Corrêa (org.). Educação rural em perspectiva internacional: instituições, práticas e formação de professores. ljuí: Unijuí, 2007, p. 79-98.

MIGUEL, Maria Elisabeth Blanck. A formação do professor para as escolas rurais no Paraná no contexto das políticas de educação nacionais e internacionais. Revista HISTEDBR On-line, n. 43, 2011, p. 21-31.

MOTA, Lucio Tadeu; NOELLI, Francisco Silva. A pré-história da região onde se encontra Maringá, Paraná. In: DIAS, Reginaldo Benedito; GONÇALVES, José Henrique Rollo. Maringá e o norte do Paraná: estudos de história regional. Maringá: UEM, 1999, p. 21-50.

OLIVEIRA, Dennilson de. A urbanização e industrialização no Paraná. Curitiba: Seed, 2001.

PARANÁ. Interventor (1932-1939: Manoel Ribas). Relatório apresentado a S. Excia. Dr. Getúlio Vargas M. D. Presidente da República pelo Snr. Manoel Ribas, Interventor Federal no Estado do Paraná. Exercício de 1932 a 1939. Curitiba, 1939.

PARANÁ. Interventor (1937-1942: Manoel Ribas). Relatório apresentado a S. Excia. Dr. Getúlio Vargas M. D. Presidente da República pelo Snr. Manoel Ribas, Interventor Federal no Estado do Paraná. Exercício de 1937 a 1942. Curitiba, 1942.

PARANÁ. Interventor (1940-1941: Manoel Ribas). Relatório apresentado a S. Excia. Dr. Getúlio Vargas M. D. Presidente da República pelo Snr. Manoel Ribas, Interventor Federal no Estado do Paraná. Exercício de 1940-1941. Curitiba, 1941.

PARANÁ. Mensagem apresentada a Assembléia Legislativa do Estado por ocasião da abertura da Sessão Legislativa de 1948, pelo Senhor Moysés Lupion, Governador do Paraná. Curitiba, PR, 1948. 
PARANÁ. Mensagem apresentada a Assembléia Legislativa do Estado por ocasião da abertura da Sessão Ordinária de 1950, pelo Senhor Moysés Lupion, Governador do Paraná. Curitiba, PR, 1950.

PARANÁ. Mensagem apresentada a Assembléia Legislativa do Estado por ocasião da abertura da $1^{\text {a }}$. Sessão Ordinária da $2^{\mathrm{a}}$. Legislatura, pelo Senhor Bento Munhoz, Governador do Paraná. Curitiba, PR, 1951a.

PARANÁ. Mensagem apresentada a Assembléia Legislativa do Estado por ocasião da abertura da Sessão Legislativa Ordinária de 1958, pelo Senhor Moysés Lupion, Governador do Paraná. Curitiba, PR, 1958.

PARANÁ. Mensagem apresentada ao Congresso Legislativo do Estado ao instalar-se a $1^{\text {a }}$ Sessão da $20^{\text {a }}$ Legislatura de 1930, por Affonso Alves e Camargo, Presidente do Paraná. Curitiba, PR, 1930.

PARANÁ. Mensagem dirigida ao Chefe de Governo Provisório da República Dr. Getúlio Vargas em 1931, pelo General Mario Tourinho, Interventor Federal no Paraná. Curitiba, PR, 1931.

PARANÁ. Parecer CEE/CEB N. 1011/2010. Estado do Paraná - Conselho Estadual de Educação - Câmara de Educação Básica. Consulta sobre as Normas e princípios para a implementação da Educação Básica do Campo no Sistema Estadual de Ensino do Paraná, bem como do processo de definição da identidade das Escolas do Campo. Curitiba, PR, 2010.

PARANÁ. Presidente de Estado (1924-1928: Caetano Munhoz da Rocha). Relatório apresentado ao Congresso Legislativo pelo Snr. Caetano Munhoz da Rocha, Presidente de Estado no Paraná. Exercício de 1924-1928). Curitiba, 1928.

PARANÁ. Relatório - A concretização do Plano de Obras do Governador Moyses Lupion (1947-1950). Curitiba, PR, 1950.

PARANÁ. Relatório apresentado ao governador Bento Munhoz da Rocha Netto, pelo Diretor do Departamento Administrativo do Oeste do Paraná (DAO), Estevam Ribeiro de Souza Netto, em 1951. Curitiba, PR, 1951b.

PASSADOR, Cláudia Souza. A educação rural no Brasil: o caso da escola do campo no Paraná. São Paulo: Annablume, 2006.

PEREIRA, Roberval Eloy. A consolidação de escolas unidocentes como política de educação para a zona rural no Estado do Paraná. São Paulo: Annablume-Fundação Araucária, 2002.

PILOTO, Erasmo. A educação é direito de todos. Curitiba: Max Roesner, 1952.

PROJETO Escolas Rurais. IBOPE Inteligência/Instituto Paulo Montenegro. Pesquisa desenvolvida para o Senar. Brasil, 2010. Disponível em: <http://www.canaldoprodutor. com.br/sites/default/files/Escolas_Rurais_no_Brasil_2010_0.pdf> Acesso em: 10 nov. 2012.

PRYJMA, Marielda Ferreira. A organização escolar: a análise da escola primária paranaense no período de 1930 a 1945. Curitiba: UFPR, 2011. 143f. Dissertação (mestrado em Educação). Universidade Federal do Paraná.

TIBUCHESKI, Jaqueline Kugler. Educação rural no município de Araucária/PR: de escolas isoladas a escolas consolidadas. Curitiba: UTP, 2011. 181f. Dissertação (mestrado em Educação). Universidade Tuiuti do Paraná. 
TOMAZI, Nelson Dacio. Construções e silêncios sobre a (re)ocupação da região norte do estado do Paraná. In: DIAS, Reginaldo Benedito; GONÇALVES, José Henrique Rollo. Maringá e o norte do Paraná: estudos de história regional. Maringá: UEM, 1999, p. 51-86. WACHOWICZ, Rui Christovam. História do Paraná. Ponta Grossa: UEPG, 2010.

ANALETE REGINA SCHELBAUER é doutora em História e Historiografia da Educação pela Universidade de São Paulo. Professora do Departamento de Teoria e Prática da Educação e do Programa de Pós-Graduação em Educação da Universidade Estadual de Maringá.

Endereço: Avenida Colombo, 5790 - bloco I-12/sala 11 - 87020-900 - Maringá -PR Brasil.

E-mail: arschelbauer@uem.br.

Recebido em 5 de maio de 2013.

Aceito em 13 de janeiro de 2014. 